\title{
A stand camera for line-of-sight recording'
}

NORMAN H, MACKWORTH ${ }^{2}$

HARVARD UNIVERSITY

The paper describes a method that has been extensively used to superpose a spot marking the position of the line-ofsight on photographs of stimulus scenes. The spot, reflected from the cornea, determines the line-of-sight with an accuracy of plus or minus $1^{\circ}$. Some of the useful measurements that can be made of fixation patterns are described. Two basic themes have guided the experimental applications: the relation between attention and the line of sight, and the association betueen peripheral and central vision. Comparisors among age groups have also demonstrated the erratic and piecemeal nature of children's visual input. Comparisons among scenes have shown that certain areas of a picture, judged highly informative, receive most of the visual fixations. More than 20 other laboratories have also used the camera in a wide range of research on perception, cognition, and psycholinguistics.

An earlier paper discussed a television eye-marker camera that recorded how the gaze of the subject moved over a display (Mackworth \& Mackworth, 1958). The camera produced an image of the scene marked with a spot of light that represented the position of the subject's line of sight. The composite picture was made by mixing the output from a television camera aimed at the scene with the output from a second television camera, which recorded a corneal reflection from the subject's eye. A simpler way of obtaining such eye-marker recordings was by optical superposition (Mackworth \& Thomas, 1962). The optical method was convenient for field research, because it

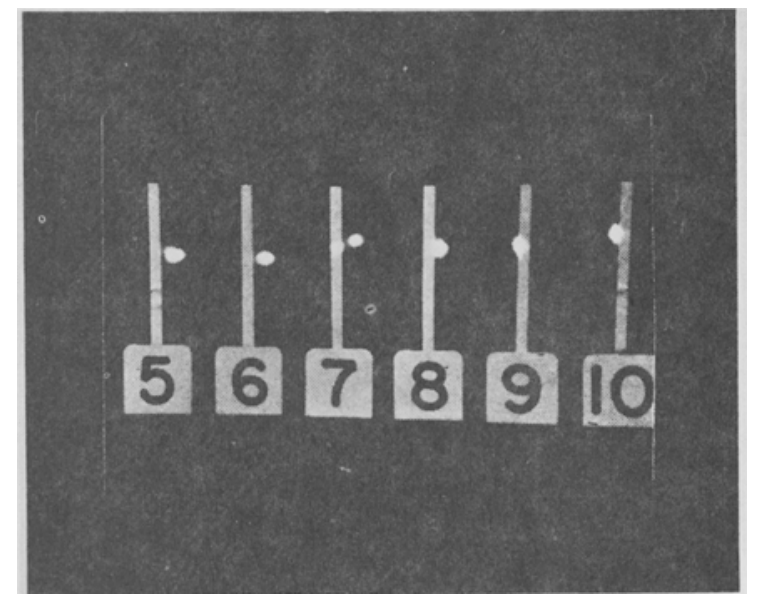

Fig. 1. Aiming accuracy for white target lines on 5-in. wide chart. Eye-spots are within plus or minus $1 / 4$ in. Since the viewing distance was $14 \mathrm{in.}$, they fell within plus or minus one degree. used a small head-mounted apparatus that allowed the subject to move his head fairly freely. Since more precise line-of-sight records are often needed for laboratory use, subsequent work has been aimed at devising a more heavily-constructed eye-marker camera to provide greater accuracy by immobilizing the subject's head. The equipment has proved versatile within the limits imposed by this condition.

The stand eye-camera relates the position of each visual fixation on a picture to stimulus details within the scene. It is economical in cost and time, because the records are convenient to analyze. For example, a single time-exposure by a Polaroid camera can record the sequence of fixations as the line of sight scans across any still picture. The same time-exposure can also, if necessary, record the arrival times of visual fixations. The stand camera does not, however, record the small involuntary drifts or tremors in the stationary line of sight. Excellent procedures are already available for this related, but technically different, problem (Riggs, Armington, \& Ratliff, 1954; Alpern, 1962; Cornsweet, 1964; and Gaarder, 1966).

\section{ACCURACY \\ 1. Accuracy of one-dimensional aiming. \\ The important feature of accuracy is registration- the precision with which the corneal reflection marks the true position of the line of sight on the stim- ulus picture. Figures 1 and 2 represent scene pictures placed at distances of 14 and 28 in. respectively}

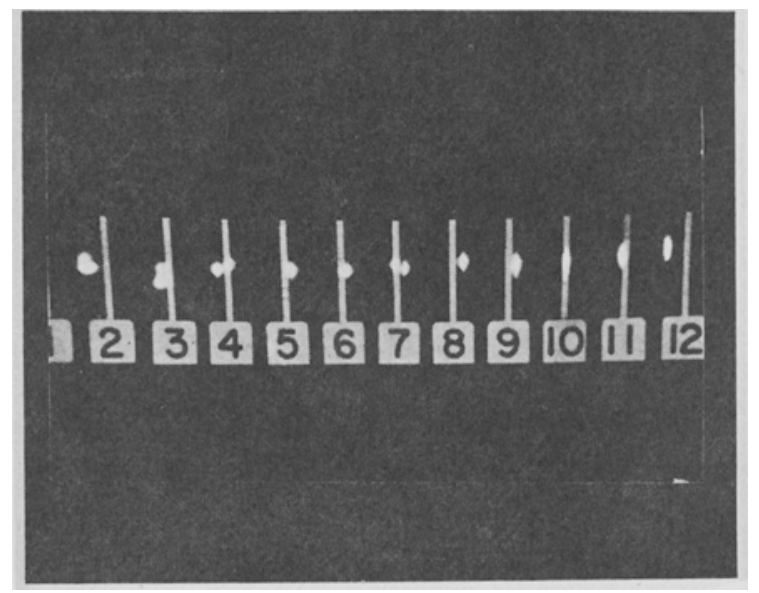

Fig. 2. Aiming accuracy for white target lines on 10-in. wide chart. Eye-spots are within plus or minus $1 / 2$ in. Since the viewing distance was 28 in., they fell within plus or minus one degree. 


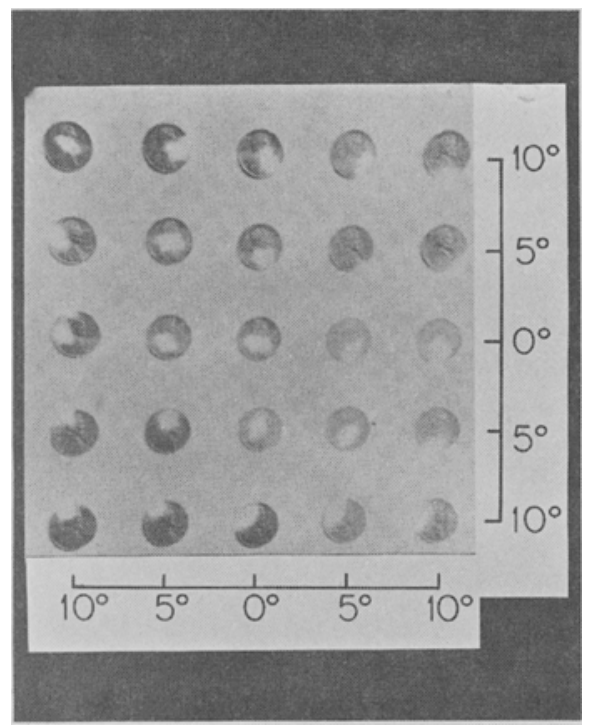

Fig. 3. Two-dimensional aiming task. Eye-spot accuracy is within plus or minus one degree of target center on all 25 readings, because each penny subtends an angle of 2 degrees. The chart is 20 degrees wide and 20 degrees high at the 22 -in. viewing distance.

from the subject. Both records demonstrate an accuracy of plus or minus 1 degree. They are representative of the accuracy observed in 4 years' work with more than 2000 eye-tracks from more than 300 subjects between the ages of 6 and 60 . The eye-camera registers accurately to within plus or minus 1 degree provided the subjects look at displays that are only 20 degrees wide and 20 degrees high.

\section{Accuracy of two-dimensional aiming.}

A display can be analyzed two-dimensionally with a similar level of precision. For instance, a $10 \times 10$ in. picture, viewed from 28 in. subtends $20 \times 20$ degrees at the eye. This picture can be subdivided for analysis into 10 columns and 10 rows, each two degrees across. The experimenter can confidently identify the position of each visual fixation within a square inch, an accuracy that implies registration within plus or minus $1 / 2$ in.-this being plus or minus 1 degree.

The recordings can therefore show which of the $100 \mathrm{sq}$. in. in a $10 \times 10 \mathrm{in.picture} \mathrm{received} \mathrm{any} \mathrm{given}$ visual fixation. In general, any $20 \times 20$ degree display can be subdivided into 10 rows and 10 columns. Such accuracy is not perfect, but it is adequate for most purposes. The remaining errors are largely due to biological factors. Thus, the aiming tolerance of the subject makes him believe he is on target when his area of regard captures the target point somewhere in the foveal net which subtends at least about 1 degree. The rest of the error is divided between slight drifts and tremors during fixation, and the misreading of the eye-spot centers during the analysis of the records.
Figure 3 shows a test display that subtended $20 \times 20$ degrees, as measured from center to center of the outlying pennies. The subject was asked to look in turn at Lincoln's chin on each of the 25 targets. Every fixation reached its penny, though not always dead on the center. Since each penny subtended 2 degrees, the size of the circle formed by each coin represented the limits of the expected error for individual fixations.

\section{General Arrangements.}

\section{DESCRIPTION}

Figures 4 and 5 give the general layout for the camera mounted on its stand. The subject sits on an armless chair with his knees under a laboratory bench. Figure 4 shows that a heavy metal baseplate, supported by the bench, carries all the equipment, including a headrest and a biting bar which are independently mounted to the same plate. The headrest and also the biting bar covered by dental wax can be adjusted and locked at a convenient height. Figure 5 emphasizes that the subject can see the whole stimulus display with both eyes.

\section{Scene Pathway.}

The stimulus picture on the vertical display board $A$ in Figs. 4 and 5 is placed at the required distance from the subject, a $10 \times 10$ in. picture at 28 in. and a $5 \times 5$ in. display at 14 in. The display board $A$ is centered on an imaginary line drawn forward along the length of the baseboard from a point perpendicularly below the left eye.

The dashed lines for the scene pathway in Fig. 5 indicate that the image of the scene at $A$ travels via the mirror-plus-prism at $B$, to enter the $25 \mathrm{~mm}$ scene lens $C$; it then passes through the beam-splitting block $\mathrm{D}$ to the recording Polaroid Camera $\mathrm{E}$. The halfsilvered mirror set obliquely in the beam-splitting block D makes two copies of the scene image. One

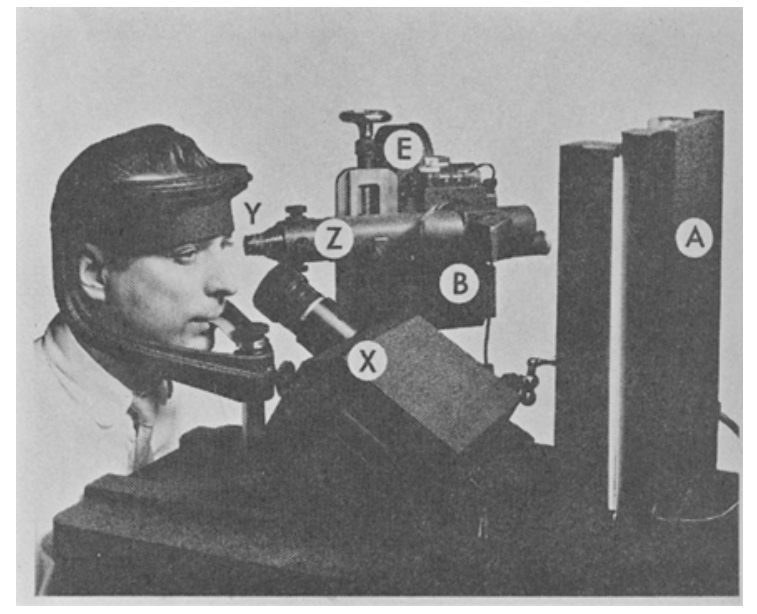

Fig. 4. General view of Stand Camera. 


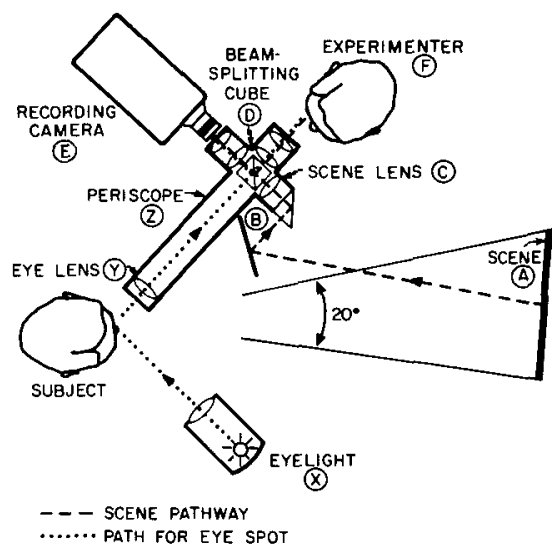

Fig. 5. Schematic view of Stand Camera.

of these images is for the recording camera $E$, and the other is for the experimenter at F. Each image travels through an identical pair of field and collimating lenses, which place it at optical infinity.

\section{Eye-Spot Pathway,}

The dotted lines in Fig. 5 trace the eye-marker pathway which starts with the eye light $X$ projecting a spot of light on the left eye. The resulting image is reflected off the cornea into the nearby eye lens Y. The eye-spot therefore travels along the horizontal periscope $\mathrm{Z}$ to enter the recording camera $\mathrm{E}$ in order to complete the composite photograph consisting of the scene image and the eye-spot.

The eye lens $Y$ has a focal length of $35 \mathrm{~mm}$. The rays of light received from the corneal reflection travel along the barrel of the periscope $Z$ to pass through the beam-splitting cube $D$. The image of the eye-spot is formed in a plane just beyond cube $D-$ see Fig. 5. This image appears in two places, on the side of the cube $D$ nearest the recording camera $E$ and also on the side nearest the experimenter $F$. The scene image has also been formed at these identical positions by the lens $C$. The recording camera $E$ and the experimenter $F$ can therefore both receive the composite image formed by stimulus scene plus eyespot.

The eye-spot moves with the change of direction of the gaze. When the eye turns, it revolves around an imaginary point which is approximately in the center of the globe of the eye, and therefore pivots further back in the head than the center of the imaginary corneal circle. This makes the corneal reflection move in the same direction as the eye. The distance moved by the spot on the composite recording is directly proportional to the eye movement within the stated limits of plus or minus 10 degrees. The distance the eye-spot appears to move across the scene can be adjusted by changing the length of the periscope barrel $\mathrm{Z}$.

\section{Recording by Polaroid Time Exposure}

The simplest form of recording is by a Polaroid camera, which takes black and white still pictures $3-1 / 4 \times 4-1 / 4$ in. in size. The aperture is left fully open at $f / 4.5$, and the lens is focused at infinity. Tensec. exposures have proved convenient, because the 30 or so fixations recorded in that time are about the most that can be recorded on one photograph without confusing the record. For these exposures the $25 \mathrm{~mm}$ scene lens $C$ is set at a narrow aperture (such as $\mathrm{f} / \mathbf{1 6}$ ), to avoid overexposing the scene relative to the eye marker. This narrow aperture produces a depth of field that obviates the need for refocusing when the position of the display is changed.

After finding the eye-spot, the eye lens on the periscope should be stopped down to ensure that the reflected eye-marker is a small, fairly well-defined dot, as in Figs. 1 and 2. The Polaroid film, rated ASA3000, will record the visual fixations, and the Polaroid Projection Slide Material at ASA800 may also be fast enough. The advantage of Polaroid Projection Slides is that the eye-spot records can be readily projected for analysis back to the original stimulus size of $10 \times 10 \mathrm{in}$. Thus, a permanent record can be prepared by projecting each pattern of fixations on an acetate sheet backed by a $10 \times 10$ in. paper grid; this paper also displays an actual-size outline drawing of the original stimulus picture. The projected fixations can be marked on this permanent acetate record sheet. Group scatter plots can be prepared by superimposing sets of individual acetate sheets.

Polaroid Infrared Film (ASA800) can also be used if an infrared filter is placed over the light source $X$ just before recording in order to prevent distracting effects from the eye light $X$. Alternatively, the fast Polaroid film, rated ASA10,000, can trace out complete eye-tracks when it is important to include the lines joining the separate fixation points.

\section{Revolving Time-Line to Mark the Sequence of Fixations.}

If a record of the temporal order of fixations is essential, a different kind of eye light can be used with the time-exposure recording. The light source $X$ is made to produce a slowly revolving line of light that takes $12 \mathrm{sec}$. to rotate clockwise around a central bright point, which indicates the position of the eyespot. The position of the line then indicates the time at which the fixation occurred.

Figure 6 illustrates how, in making a careful search along a coastline, a subject started at the top of the picture and then made 18 successive fixations, moving slowly down the picture. The pointer rotated from the vertical or $120^{\prime}$ clock position to the 6 $0^{\prime}$ clock position, indicating $6 \mathrm{sec}$. of elapsed time.

Similarly, in Fig. 7, another subject, on a reading task, had a regular series of fixations along the first two lines of print, but the third line contained 


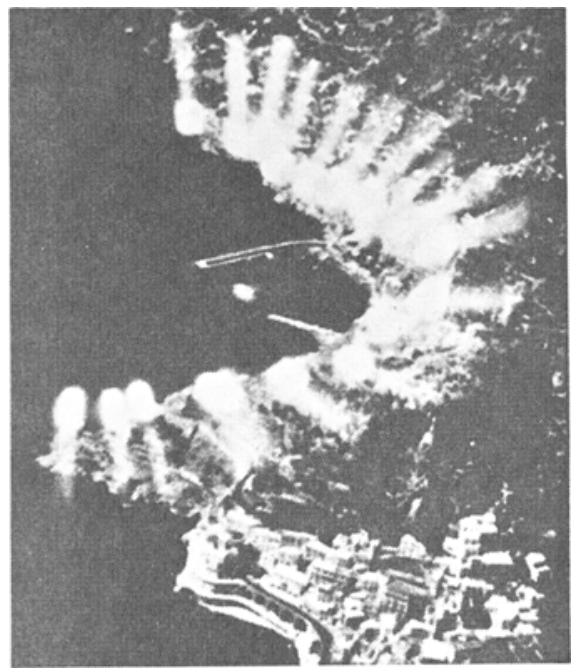

Fig. 6. Demonstration record of the revolving eye-line timemarker on pictorial materials. The recording of this sequence of fixations down a coastline lasted for $6 \mathrm{sec}$. The clock hand tumed from $12 o^{\prime}$ clock to $6 o^{\prime}$ clock.

the unfamiliar word "tatterdemalion," which caused a "double-take," or regressive movement. The effect of this backward glance was to alter the regular progression of pointer slopes seen with the first two lines of print. On the third line the actual sequence has been overprinted to number off the fixations in the order in which they were made. This sequence began with a forward pass over the difficult word $(1-2-3)$. Then came a short backward movement (3-4), followed by a complete backward glance $(4-5)$. Finally the subject moved forward to finish the line $(5-6-7-8-9)$.

\section{OPERATION OF CAMERA}

The effectiveness of the camera depends on the following procedures.

\section{Fixing the Head in Position.}

The head support and the bite bar are both essential for accurate work.

\section{Finding and Focusing the Eye-Sp of by Aiming the Eye Lens.}

Control handles are manipulated to bring the eye lens $Y$ of the periscope to about 1 in. from the left eye and about 1 in. above eye level. These adjustments are made while the subject is fixating a white cross centered on the display board. The experimenter then aims the eye lens $\mathrm{Y}$ at the bright corneal reflection by looking along the top of the periscope barrel $\mathrm{Z}$ and by moving the periscope either left or right with a third manual control. The room and scene lights are kept dim, but the eye light is set at full intensity. While the subject is still fixating the white cross, the experimenter looks through his eyepiece and slowly lowers the periscope, watching all the time for the eye-spot, which is often a large, round, moon-like and glinting object. Once seen, the eye-spot is immediately focused and placed centrally by further slight adjustments of the controls. Next, the size of the eye-spot is reduced by closing the iris aperture on the eye lens $Y$ to about $f / 11$, and also by dimming the eye light $X$ to a level that just produces a clear photographic image.

\section{Registering the Eye-Spot on the Stimulus Scene.}

The eye-spot is then adjusted by the manual controls until it falls on the center of the white cross in the composite picture seen by the experimenter. An experienced operator can find and focus and register the eye-spot in about $20 \mathrm{sec}$. (In many experiments, four dots each $2-1 / 2$ in. away from the center dot are used to vary the fixation point in order to avoid artificial concentrations of fixations near the center of the stimulus picture.)

\section{Instructions for the Visual Task.}

The subject is encouraged to feel free to look anywhere on the pictures that he will be shown, and also to blink at will. But he is warned not to move his head while viewing any of the stimulus displays. He is often given a rather general, but neutral task, such as to decide which pictures he likes best. Alternatively, more specific instructions may be given for visual detection or recognition tasks. All oral

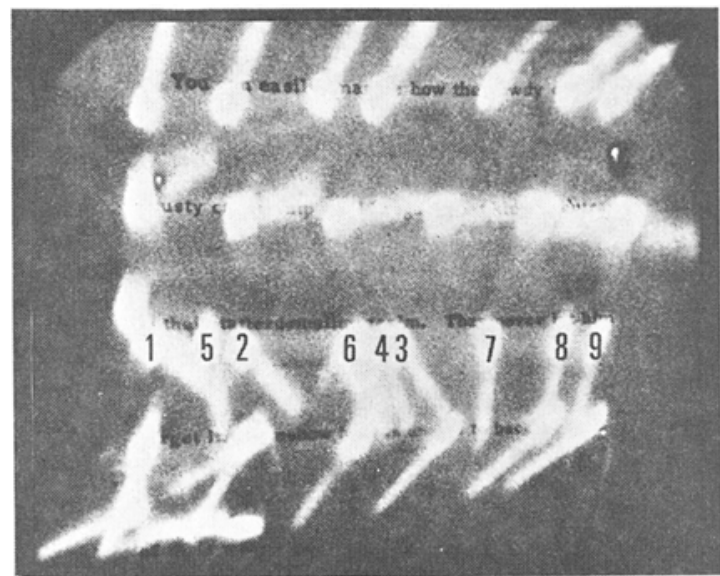

Fig. 7. Reading record with time-marker showing regular succession of fixations along the first two lines of typescript. The third line shows the subject stumbling over an incomprehensible word and making regressive movements. The actual disordered sequence has subsequently been numbered off on the recording. 
instructions should be standardized, as they obviously have a marked effect on visual behavior.

\section{Experimental Recording of Eye-Spot on Scene.}

An assistant presents the stimulus display at the moment the experimenter starts the time exposure. The experimenter refocuses the eye-spot during the recording period, if necessary. Finally, when the 10 sec. of the time exposure have elapsed, the experimenter closes the camera shutter and the assistant flips down the test cross to hide the stimulus display.

\section{Checking Alignment after Each Stimulus Presentafion.}

In order to confirm that the marker remained in registration with the scene during the recording, the subject is asked to refixate the center of the test cross.

\section{ALTERNATIVE METHODS \\ 1. Stimulus Presentation by Slides or Motion Picture Pro- jection.}

Stimulus materials such as slides or motion pictures can be presented by projection on a viewing screen when the display stand A (Fig. 4) has been removed. The subject can then look horizontally forward and see displays as large as $5 \mathrm{ft}$. wide on a vertical screen centered at eye height provided the screen is placed $14 \mathrm{ft}$. from the eyes.

\section{Recording by Motion Picture Camera.}

With projection slides, the simple Polaroid camera can photograph the successive scenes with the fixations elicited on each occasion. But when a moving picture provides the stimulus material, a $16 \mathrm{~mm}$ movie camera replaces the Polaroid camera to record on either Kodak Tri-X or Kodak High Speed Infrared film.

\section{Single-Shot $16 \mathrm{~mm}$ Film Strip Recording.}

Continuous motion picture recordings can, however, be tedious to analyze and store. When the investigation involves many readings, a $16 \mathrm{~mm}$ movie camera should be modified to record the observations by a series of 1-sec. time exposures. The resulting records on short film strips are easy to handle and to read by a $16 \mathrm{~mm}$ single-frame projector. Only static stimulus scenes can be studied by this procedure.

\section{Data Processing by Computer.}

\section{(1) Data Handling}

The position of any fixation on a 10 by 10 matrix can be expressed as a two-figure number or $x-y$ coordinate. The 30 coordinates of the fixations on a $10-\mathrm{sec}$. photographic recording can easily be read off by eye and listed in about a minute. They can then be entered into a computer for data analysis. Most of the delays in data handling arise from minor calculations and tabulations. There is therefore no great need to automate the actual reading of the $x-y$ coordinates, since this accounts for only about one-tenth of the data analysis time. But analog-to-digital optical readers can soon automatically process the $16 \mathrm{~mm}$ film strips if very many readings are being scored.

(2) Automatic Grid Reference Reading

Usually the only situations that justify completely automatic position detection are problems requiring very accurate fixation times. A television-scan-spot-detector can then be attached to the camera to record automatically all arrival times for individual fixations to within plus or minus $8 \mathrm{msec}$. on magnetic tape recordings. A computer may later analyze the readings to provide tables of data completely analyzing each eye track spatially as well.

\section{A Television Viewfinder.}

When a long series of recordings has to be undertaken, it is helpful to the experimenter to be able to view the composite eye-spot-on-scene image on the screen of a 17-in. television monitor. This can be arranged by placing a closed-circuit television camera at the eyepiece $\mathrm{E}$. Such direct and immediate eyewatching can soon support or refute hunches about the nature of the visual behavior-before the photographic records have been examined for quantitative details. The television facility is especially useful during exploratory experiments and clinical studies.

\section{RESEARCHES WITH THE CAMERA}

The eye-spot camera has been devised at a time when there is a tendency to regard visual perception as a data-processing procedure that starts with information extraction (Bminer, 1957; Pribram, 1960; Forgus, 1966; Posner, 1966; Hilgard \& Bower, 1966; Staniland, 1966). Attempts have therefore been made to understand more fully some of the relations between the physiological and psychological aspects of vision. For example, attention and the line of sight are found to be closely related, although there is no one-to-one association (Mackworth \& Bruner, 1966).

Measuring the spatial features of eye tracks. The devising of new stimulus displays to elicit the appropriate visual behavior often proved the most difficult aspect of defining the given problem in experimental terms. Once these difficulties have been solved, the following spatial measures may be useful in analyzing eye tracks across the various stimulus pictures. (Records of sequence and duration may also be required in some studies.)

(a) density of fixations per square inch of pictureas group scatter plots.

(b) rated search score - the judged informativeness of each square inch of the picture may be obtained from a separate group of subjects (Mackworth \& Bruner, 1966). Each fixation can therefore be assigned an informativeness value, and the sum of these fixation values is the rated search score for any given eye-track or group. This score indicates to what extent 
the gaze fell on highly informative areas (Mackworth \& Morandi, 1966).

(c) picture coverage - the total length of the eyetrack in 10 sec,-alternatively, the number of squares fixated (Luborsky, Blinder, \& Schimek, 1965).

(d) effective search score-a combination of rated search score per track and picture coverage (Mackworth \& Bruner, 1966).

(e) repeat index of consistency-a measure of the tendency to re-fixate the same regions when the picture is shown a second time.

(f) length of eye movements -especially the incidence of short steps (less than 6 degrees) and of long leaps ( 6 degrees or longer).

(g) direction of eye movements -particularly any long leaps between two widely separate regions which have to be mentally related.

The author and others have used these measures to analyze records under five main headings, as follows: (1) The Useful Field of View

(a) The relation between foveal and peripheral vision. During the relatively casual inspection of pictures by subjects required to express simple preferences, redundant contours and textures received few fixations. Peripheral viewing often determined where not to look. Foveal vision was reserved for a few regions of informative detail (Mackworth \& Morandi, 1966).

(b) The size of the useful field of view. Mackworth (1965) showed that in tachistoscopic presentation, the presence of extra details reduced the number of letters that could be reported. This finding was extended to scanning situations. The scanning pattern revealed by the camera showed that the size of the visual field was reduced when extra details were added. The size of the useful field during scanning was limited by the amount of detail that could be processed in each fixation (Mackworth \& Hiebert, 1966).

\section{(2) Visual Perception}

(a) Visual concentration within a given picture. Selective visual attention is particularly noticeable in eye tracks taken during the inspection and recognition of pictures. Studies with 10 different scenes have indicated that people will usually fixate the areas within a picture that others have judged to be the most informative regions for that particular display (Mackworth \& Bruner, 1966; Mackworth \& Morandi, 1966).

(b) Sequence of visual inputs from a picture. Subjects show great consistency in selecting certain areas of a picture for inspection. But there appears to be no preferred sequence in which these areas are inspected, in contrast with reading. The order in which the visual fixations are made seems to matter no more than the sequence in which a series of shots are taken for a motion picture. Shoot now and think later! is the cry. It is apparently much easier to reassemble the pleces into the appropriate pattern after all the data have entered the brain (Lashley, $1960)$.

(3) Cognitive Researches

Records of the line of sight can indicate not only the stimuli that catch the eye, but also the stimuli that the brain attempts to relate cognitively. One instance of these cognitive effects was found when the direction of the long eye movements across a picture completely changed from vertical to horizontal as soon as the nature of the vertical array of blurred images on view had been identified (Mackworth \& Bruner, 1966).

Cognitive comparisons have been made between subjects trying to comprehend an out-of-focus picture and other subjects casually inspecting the same picture when they had just seen a well-focused version of the same image. With efforts toward comprehension, subjects are more likely to select the most informative regions for study. Since this extra thinking takes time, these "comprehension" subjects make longer and fewer fixations during the 10-sec. periods.

There are two ends to the line of sight which acts as a direct link between the external stimuli at one end and the internal schemata at the other. Line-ofsight recordings may have a special place during the earliest stages of learning while such schemata or models are being formed. McCormack and Haltrecht (1965) have demonstrated a growing visual concentration on the first words during paired-associate learning.

Current researches by Mehler, Bever, and Carey (1966) have also shown that the visual fixation patterns made during reading often reflect the surface phrase structures being used by readers who fixate the first half of the phrase structure constituents. This pattern of fixation was altered when a different phrase structure was imposed on the same ambiguous series of printed words by altering the psychological set just before the subjects read the words.

Comprehension difficulties during the reading of verbal text give regressive movements, as in Fig. 7-this reduces the average number of words per visual fixation. Both these and other measures are affected by changing the extent to which the text resembles normal English. Prolonged experience with the English language has produced well-established word sequences. When the stimulus text is changed in stages from random words to plain English, regressive movements become fewer and the eye movements increase in length. There are more words per fixation because the succeeding words are usually more predictable (Bruner \& Cromer, 1966; Morton, 1964).

Cognitive delays in reading comprehension are known 
to be reflected by longer visual fixation times (Carmichael, 1957). In the study in which the requirement for comprehension increased the average fixation items, the average fixation times increased by nearly $100 \mathrm{msec}$. compared with the inspection conditions for the same pictures. Recent analysis of the effects of information overload during high speed scanning has shown that the widening of the display to be scanned from a narrow strip to a broad pathway also lengthens the average fixation times (Mackworth \& Hiebert, 1966).

\section{(4) Adults versus Children}

Children differ from adults in four main ways when they look at pictures (Mackworth \& Bruner, 1966).

(a) They shown more short eye movements. (b) They concentrate on less informative details. (c) They show less consistency, either on a second viewing of the same picture, or between different children. (d) Children also exhibit piecemeal perception, in the sense that they tend to linger on unimportant details. Their eye tracks sometimes trace out simple contours which adults process by peripheral vision. This pinpointing on details does not therefore support the age-old assumption that children's perception is global (Kagan, 1966).

\section{(5) Practical Applications}

The series of problems being studied with the aid of the stand camera range from blue-sky abstraction to red-blood practicality. Sereral applied studies complete this illustrative sample drawn from the whole spectrum of human research.

(a) Psychiatric studies have confirmed that the first line of perceptual defense is the line of sight. Perceptual defense is more than a matter of limited awareness starting after the stimuli have entered the visual system; perceptual defense begins at the sensory mechanisms. The personalities of psychologically normal secretaries, students, and housewives clearly affected their eye movements when they looked at emotionally-disturbing pictures of either aggressive or sexual scenes. Certain objective personality tests divided the test group into repressors and isolators. The repressors were often unable to recall these emotionally-toned items from the displays. Repressors also looked around much less than isolators on the pictures; for example, about 5 percent of the area of the pictures might receive direct fixations from repressors instead of the more usual 10-15 percent. The repressors were therefore less venturesome especially with threatening pictures. The average distance between their fixations was slightly shorter, although the same number of fixations were made by both groups of subjects during the $10 \mathrm{sec}$. exposure. In addition, emotionally-arousing displays giving a high galvanic skin response were avoided by subjects who looked more frequently at the background of such pictures (Luborsky, Blinder, \& Mackworth, 1963, 1964; Luborsky, Blinder, \& Schimek, 1965). Sometimes a subject will strongly deny having looked at emotionally-toned features in a pictureeven when the Polaroid record undoubtedly showed several fixations on these particular items in question. The beginnings of visual awareness (as indicated by the oral report of a faintly-illuminated word gradually appearing on the screen) are accompanied by a concentration of visual fixations in that area (Luborsky, Rice, Phoenix, \& Fisher, 1966).

Investigators are also trying to use visual scanning records and other tests (such as size estimation) to assist clinicians to discover the main diagnostic dimensions of schizophrenia. The clinical differences and also features in the case history are being related to the visual records, such as the number of fixations made during $10 \mathrm{sec}$. of a size-estimation task (Silverman, 1964, 1966).

(b) Medical studies with the stand camera have increased interest in problems related to the effects of brain damage on eye-movement behavior (Teuber et al, 1960; Tyler, 1966; Luria et al, 1963). Of particular importance for general knowledge is the relation between central and peripheral viewing, when the latter is so grossly disturbed by brain injury or disease that marked tunnel vision is experienced by the patient.

(c) Educationally oriented research has shown that impulsive children fail to sample the visual data adequately before offering a guess in answer to a simple pattern-matching problem. A long-term inquiry has also been started on clarity of presentation in teaching-machine displays for programmed learning.

(d) Space researches have examined some aspects of visual search and have considered why some aerospace landmarks in lunar and terrestial photographs appear to be so outstandingly successful. They have also measured the effects of information overload in lengthening fixations (Mackworth \& Hiebert, 1966).

(e) Military work has analyzed why photo-interpreters sometimes detect less than half the important features in aerial photographs (Zeidner, 1962). Other looking-without-seeing research has demonstrated that people can often fail to report dial-presented events even when they are fixating them directly (Mackworth, Kaplan, \& Metlay, 1964).

(f) Transport studies by Crowley, Gruber, and McFarland (1966) include a series of road safety researches with motion picture stimuli involving several standard driving problems aimed at elucidating driver reactions to emergencies. This study has also shown a need for equipment design to optimize turn- and stop-lights on automobiles.

(g) Irban design and architectural research work has employed motion pictures to consider how the view from the road affects the pattern of fixations under laboratory conditions. The relation between visual scanning and the particular roadside structures that appear in the movie has been investigated with reference to the information subsequently recalled, recognized or reproduced (Carr, 1966). In 
another investigation, subjects are shown a connected series of projection slides of central city traffic and roadside scenes, in order to aid the city planners. Architectural alternatives and preferences could equally well be the object of inquiry; a general alternative choice could be provided among a number of potential designs all displayed at the same time.

(h) Aesthetic problems now being examined in painting and creative photography complete this enumeration of some of the topics being examined by eyecamera methods. Exploratory investigations of artistic designs can certainly raise more problems than they solve, but they help to formulate answerable questions on problems debated for centuries without end or issue. Some preliminary experiments have compared the extent to which artists such as Durer, Goya, and Degas have been able to create patterns that concentrate the gaze on a few regions within each pictureespecially, for example, their use of blank predictable areas and repetitive patterns which do not require foveal vision.

\section{CONCLUSIONS}

(1) Eye-movement studies reveal a great deal about the ways in which subjects take in and think about visual information.

(2) The stand camera gives immediately available records of how a subject scans a display. It produces a composite picture of the display with the eye fixations superimposed upon it.

(3) The optical superposition of the eye-spot is accurate to within plus or minus 1 degree. The residual error is mainly due to the foveal field of view and also partly due to eye tremor and eyespot size. The accuracy is adequate for the purpose of relating details in the stimulus display. For example, a $10 \times 10$ in. picture held at arm's length can be subdivided for this analysis into the 100 separate sq. in. that together comprise the whole scene.

(4) With an unchanging stimulus display, records of line of sight may be made by a single Polaroid time exposure lasting $10 \mathrm{sec}$. Then the position and also the arrival times of successive fixations can best be indicated by reflecting a line of light off the cornea (rather than an eye-spot); this form of eye-marker can then indicate elapsed time by successive changes in the slant of the recorded line. Sometimes, however, it may be even more convenient to record each test spell by a series of $1-\mathrm{sec}$. time exposures recording eye-spots in the form of $16 \mathrm{~mm}$ film strips; this is especially needed, for example, for those who wish later to use an optical scanner to read many eye-spot positions entirely automatically. With moving displays, fixations should be registered as eye-spots by continuous motion picture recordings.

(5) While the recordings are being made, the experimenter can watch the eye moving across the display.
(6) The use of the fixed-mounted camera requires a fixed head position in order to maintain accuracy and simplify data analysis. This limitation prevents the use of the equipment for real life tasks in which the subject must be able to move his head or alter his posture.

(7) At least 20 laboratories in the United States and Europe now use the stand camera. Each investigator has analyzed a different aspect of human information processing, and the results cover a wide range of human performance. By studying the interactions between person and picture, and also between person and text, such experiments are starting to define the nature of selective visual attention.

\section{References}

Alpern, M. Movements of the eyes. In H. Davson (Ed.), The eye. Vol. 3. New York: Academic Press, 1962.

Bruner, J. S. On perceptual readiness. Psychol. Rev., 1957,64, 123-152.

Bruner, J. S., \& Cromer, R. Personal communication, 1966.

Carmichael, L. Comprehension time, cybernetics, and regressive eye movements in reading. In Proc. 15th Int. Cong. Psychol., Brussels, 1957, 126-127.

Carr, S. Personal communication, 1966.

Cornsweet, T. N. Measuring movements of the retinal image with respect to the retina. In W. E. Murry \& P. F. Salisbury (Eds.), Biomedical sciences instrumentation. Vol. 2. New York: Plenum Press, 1964.

Crowley, T., Gruber, B., \& McFarland, R. A. Personal communication, 1966.

Forgus, R. H. Perception: The basic process in cognitive development. New York: McGraw-Hill Book Co., 1966.

Gaarder, K. Fine eye movements during inattention. Nature, 1966 209, 83-84.

Hilgard, E. R., \& Bower, G. H. Theories of learning. (3rd ed.) New York: Appleton-Century-Crofts, 1966.

Kagan, J. Personal communication, 1966.

Lashley, K. S. The problem of serial order in behavior. In F. A. Beach et al (Eds.), The neuropsychology of Lashley. New York: McGraw-Hill Book Co., 1960

Luborsky, L., Blinder, B., \& Mackworth. N. H. Eye fixation and recall of pictures as a function of GSR responsivity. Percept. mot. skills, $1963,16,469-483$.

Luborsky, L., Blinder, B., \& Mackworth, N. H. Eye fixation and the contents of recall and images as a function of heart rate. Percept. mot. Skills, 1964, 18, 421-436.

Luborsky, L., Blinder, B., \& Schimek, J. Looking, recalling, and GSR as a function of defense. J. abnorm. Psychol., 1965, 70, 270-280.

Luborsky, L., Rice, R., Phoenix, D., \& Fisher, C. Eye fixation behavior as a function of awareness, 1966. (to appear)

Luria, A. R., Pravdina-Vinarskaya, E. N., \& larbus, A. L. Disorders of ocular movement in a case of simultanagnosia. Brain, $1963,86,219-228$.

Mackworth, N. H. Visual noise causes tunnel vision. Psychon. Sci., $1965,3,67-68$.

Mackworth, N. H., \& Bnuner, J. S. Selecting visual information during recognition by adults and children. Mimeographed monograph, Harvard Center for Cognitive Studies, 1966.

Mackworth, N. H., \& Hiebert, Joyce M. Measuring the useful field of view during visual search, 1966. (in preparation)

Mackworth, N. H., Kaplan, I. T., \& Metlay, W. Eye movements during vigilance. Percept. mot. Skills, 1964, 18, 397-402.

Mack worth, N. H., \& Mackworth, Jane F. Eye fixations recorded 
on changing visual scenes by the television eye matker. J. Opt. Soc. Amer., 1958, 48, 439-445.

Mackworth, N. H., \& Morandi, A. J. The gaze selects within pictures, 1966. Percept. \& Psychophys., in press.

Mackworth, N. H., \& Thomas, E. L. Head-mounted eye-marker camera. J. Opt. Soc. Amer., 1962, 52, 713-716.

McComack, P. D., \& Haltrecht, E. J. Two-state paired-associate learning and eye movements. Science, 1965, 148, 1749-1750.

Mehler, J., Bever, T., \& Carey, P. What we look at when we read, 1966. (submitted for publication)

Morton, J. The effect of context upon speed of reading, eye move ments and eye-voice span. Quart. J. exp. Psychol., 1964, 16 340-354.

Posner, M. Components of skilled performance. Science, 1966, 152 , 1712-17 18.

Pribram, K. H. A review of theory in physiological psychology. Annu. Rev. Psychol., 1960, 11, 1-40.

Riggs, L. A., Armington, J. C., \& Ratliff, F. Motions of the retinal image during fixation. J. Opt. Soc. Amer., 1954, 44, 315-321.

Silverman, J. The problem of attention in research and theory in schizophrenia. Psychol. Rev., 1964, 71, 352-379.

Silverman, J. Variations in cognitive control and psychophysiological defense in the schizophrenias. Psychosom. Med., 1966, in press.
Stmiland, A. C. Patterns of redundancy: A psychological study. New York: Cambridge University Press, 1966.

Teuber, H-L., Battersby, W. S., \& Bender, M. B. Visual field defects after penetrating missile wounds of the brain. Cambridge: Harvard University Press, 1960.

Tyler, R. Personal communication, 1966.

Zeidner, $d$. Requirements for research in psychological factors in image interpretation. In $M$. A. Whitcomb (Ed.), Visual problems of the armed forces. Washington, D. C.: Armed Forces-NRC Committee on Vision, NAS-NRC, 1962.

\section{Nates}

1. The research reported herein was supported by the National Science Foundation, Contract No. GS-192, to Harvard University, Center for Cognitive Studies, and by the Cooperative Research Program of the Office of Education, U. S. Department of Health. Education, and Welfare Contract No. OE-4-10-136, Project No. E020, to Harvard University, Center for Cognitive Studies, and also by the National Aeronautic and Space Administration Research Grant NsG7 18 to Harvard University, Guggenheim Center for Aerospace Health and Safety.

2. I thank both Professor Jerome S. Bruner and Dr. Jane F. Mackworth for many valuable comments made during these researches.

(Accepted for publication December 23, 1966.) 